\title{
Defective immunogenic cell death of HMGB1-deficient tumors: compensatory therapy with TLR4 agonists
}

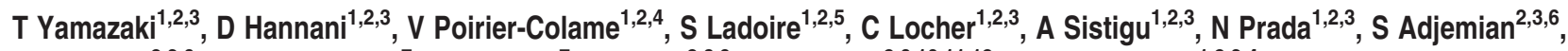 \\ JPP Catani ${ }^{2,3,6}$, M Freudenberg ${ }^{7}$, C Galanos ${ }^{7}, F_{\text {André }}^{2,8,9}$, G Kroemer $^{2,6,10,11,12}$ and L Zitvogel ${ }^{*, 1,2,3,4}$
}

Immunogenic cell death induced by anticancer chemotherapy is characterized by a series of molecular hallmarks that include the exodus of high-mobility group box 1 protein (HMGB1) from dying cells. HMGB1 is a nuclear nonhistone chromatin-binding protein. It is secreted at the late stages of cellular demise and engages Toll-like receptor4 (TLR4) on dendritic cells (DCs) to accelerate the processing of phagocytic cargo in the DC and to facilitate antigen presentation by DC to $T$ cells. The absence of HMGB1 expression by dying tumor cells exposed to anthracyclines or oxaliplatin compromises DC-dependent T-cell priming by tumor-associated antigens. Here, we show that transplantable tumors exhibiting weak expression of nuclear HMGB1 respond to chemotherapy more effectively if the treatment is combined with the local or systemic administration of a highly purified and physiochemically defined and standardized lipopolysaccharide solution, which acts as a high-potency and exclusive TLR4 agonist, called Dendrophilin (DEN). The synergistic antitumor effects mediated by the combination of chemotherapy and immunotherapy relied upon the presence of the MyD88 (myeloid differentiation primary response gene) adapter of TLR4 (but not that of the TIR-domain-containing adapter-inducing interferon- $\beta$ adapter), in line with the well-characterized action of DEN on the MyD88 signaling pathway. DEN and anthracyclines synergized to induce intratumoral accumulation of interferon- $\gamma$-producing $\mathrm{CD}^{+}{ }^{+}$and $\mathrm{CD}^{+}{ }^{+}$T lymphocytes. Moreover, DEN could restore the immunogenicity of dying tumor cells from which HMGB1 had been depleted by RNA interference. These findings underscore the potential clinical utility of combination regimens involving immunogenic chemotherapy and certain TLR4 agonists in advanced HMGB1-deficient cancers.

Cell Death and Differentiation (2014) 21, 69-78; doi:10.1038/cdd.2013.72; published online 28 June 2013

$\mathrm{We}^{1}$ and others ${ }^{2}$ have described the concept of 'immunogenic cell death' (ICD) in cancer as a modality of cell demise triggered by a minority of cytotoxic agents that ultimately elicit an antitumor-specific T-cell immunity. Some anticancer treatments, such as ionizing irradiation or chemotherapy with anthracyclines, oxaliplatin or cyclophosphamide are far more efficient when applied to immunocompetent than to immunodeficient mice developing tumors from the same cellular origin. This observation prompted the search for the molecular links between tumor cell death, stimulation of pathogen recognition receptors and natural or adaptive immunity. Preclinical data revealed that dying tumor cells can emit a series of danger signals (so called 'damage-associated molecular patterns' (DAMPs) that dictate the recruitment and activation of specific myeloid immune effectors, hence triggering the first line of the innate response. ${ }^{3}$ Such DAMPs include metabolic alterations (extrusion of ATP into the extracellular space), ${ }^{4,5}$ alterations of the cell surface (such as the exposure of calreticulin on the plasma membrane ${ }^{6}$ and changes in the pericellular microenvironment (such as the nuclear and cellular exoduses of the chromatin-binding protein, high-mobility group box-1, HMGB1) ${ }^{7}$ that ultimately ignite an anticancer immune response. Such an immune response involves a complex hierarchy of immune effectors, including monocyte-derived dendritic cells (DCs) producing interleukin-1 $\beta, \gamma / \delta$ T-cells producing interleukin-17 and conventional $\mathrm{CD}^{+} \alpha / \beta$ T-cells producing interferon- $\gamma($ IFN- $\gamma){ }^{4,8,9}$

Although Toll-like receptors (TLRs) were originally described to detect microbial products only, ${ }^{10}$ endogenous danger signals from dying cells can bind TLRs as well, and, hence, they can modulate adaptive immune responses. ${ }^{11}$ The systematic screening for a role of TLRs in the efficacy of chemotherapy or radiotherapy led us to unveil the elective contribution of TLR4 in these antitumor effects. ${ }^{7}$ TLR4 present on the surface of DCs recognizes its endogenous ligand HMGB1, which is released from dying tumor cells, and this

\footnotetext{
${ }^{1}$ INSERM U1015, Villejuif, France; ${ }^{2}$ Institut de Cancérologie Gustave Roussy, Villejuif, France; ${ }^{3}$ University of Paris Sud XI, Villejuif, France; ${ }^{4}$ Center of Clinical Investigations in Biotherapies of Cancer (CICBT), Villejuif, France; ${ }^{5}$ Department of Medical Oncology, Centre Georges François Leclerc, Dijon, France; ${ }^{6}$ INSERM U848, Villejuif, France; ${ }^{7}$ Max-Planck-Institute of Immunobiology, Freiburg, Germany; ${ }^{8}$ INSERM U981, Villejuif, France; ${ }^{9}$ Department of Medical Oncology, IGR, Villejuif, France; ${ }^{10}$ University of Paris Descartes, Sorbonne Paris Cité, Paris, France; ${ }^{11}$ Equipe 11 labellisée Ligue Contre le Cancer, Centre de Recherche des Cordeliers, Paris, France and ${ }^{12}$ Pôle de Biologie, Hôpital Européen Georges Pompidou, Paris, France

*Corresponding author: L Zitvogel, Department of Immunology, INSERM U805, Institut de Cancérologie Gustave Roussy, 114 rue Edouard Vaillant, Villejuif 94805 , France. Tel: +33 1421150 41; Fax: +33 1421160 94. E-mail: zitvogel@igr.fr Keywords: TLR4; immunogenic cell death; chemotherapy; Dendrophilin; cancer Abbreviations: DAMP, damage-associated molecular pattern; DC, dendritic cell; DEN, Dendrophilin; HMGB1, high-mobility group box-1; ICD, immunogenic cell death; IFN, interferon; MyD88, myeloid differentiation primary response gene; TLR, Toll-like receptor; TRIF, TIR-domain-containing adapter-inducing interferon- $\beta$; RAGE, receptor for advanced glycation end products

Received 29.1.13; revised 06.5.13; accepted 27.5.13; Edited by M Piacentini; published online 28.6.13
} 
ignites a MyD88 (myeloid differentiation primary response gene)-dependent signaling pathway essential for the perception of ICD. The TLR4/MyD88 pathway elicited by HMGB1 inhibits the fusion between phagosomes and lysosomes, thereby facilitating tumor antigen processing, which is required for the induction of restimulation of cellular immune responses against cancer cells. ${ }^{7,12}$ Hence, the immunogenicity of tumor cells exposed to anthracyclines is lost in mice presenting with genetic defects in TLR4 (such as the natural $\mathrm{C} 57 \mathrm{C} 3 \mathrm{H}$ t/r4 mutation or knock out of the T/r4 gene induced by
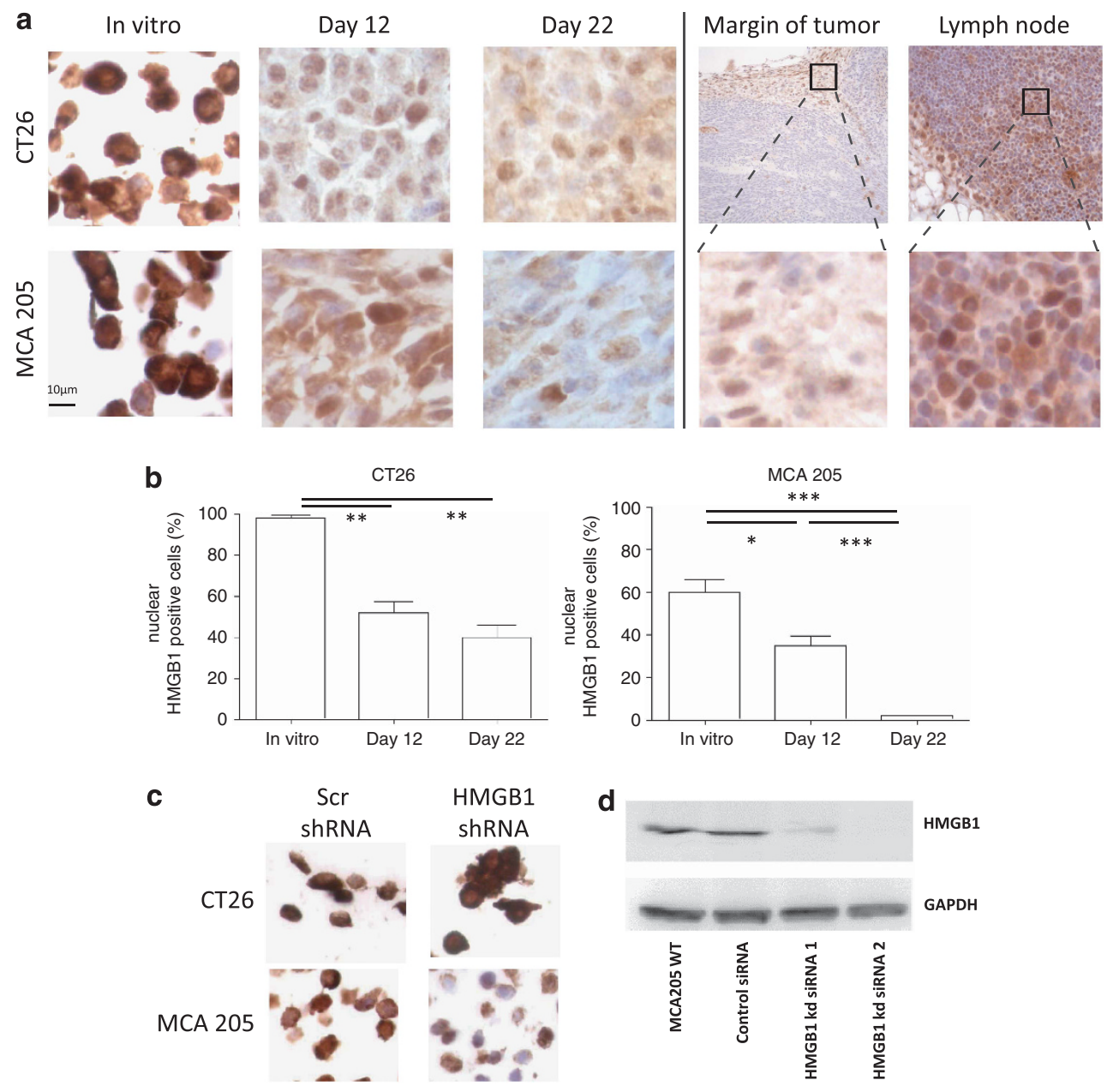

e

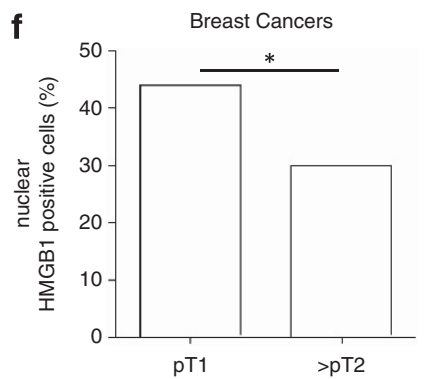

Figure 1 Nuclear HMGB1 is weakly expressed in established mouse tumors. (a) Typical staining of paraffin-embedded CT26 and MCA205 cell lines cultured in vitro, or after ex vivo conditioning and at day 12 and 22 post inoculation in BALB/c or C57BL/6 mice using anti-HMGB1 Ab. Control staining patterns using an isotype control antibody indicated no specific labeling of nuclei or cytoplasms (not shown). As internal control, marginal zone of the MCA205 tumor and lymph node showing nuclei HMGB1 staining are depicted. (b) Enumeration of positive nuclear staining patterns in cell lines or in vivo established CT26 and MCA205 tumors at day 12 or 22 out of 100 tumor cells observed in five different field at $\times 20$ magnification. (c) Typical staining of paraffin-embedded CT26 and MCA205 cell lines transfected with siRNA HMGB1. (d) Western blot showing the loss of HMGB1 expression in polyclonal CT26 and MCA205 tumors transfected with siRNA HMGB1 (but not with scrambled siRNA controls). (e and f) Using immunohistochemical analysis, we studied the nuclear expression of HMGB1 in tumor samples from 232 patients with localized BC treated in two French cancer center (Institut Gustave Roussy, Villejuif and centre Georges François Leclerc, Dijon France). Patients were treated by surgery followed by anthracycline-based adjuvant chemotherapy, radiotherapy if required. In 84 tumors (36\%), BC cells harbored a strong nuclear expression (e, left panel), whereas 148 (64\%) tumors had no nuclear expression of HMGB1 (e, right panel). (f) Frequency of nuclear HMGB-1-positive breast tumor cells according to tumor size (pathologic tumor stage, e.g.: pT1 if tumor size was $\leq 2 \mathrm{~cm}$ and at least pT2 if tumor size was $>2 \mathrm{~cm}$ ). ANOVA with the Newman-Keuls multiple comparison test or the $\chi^{2}$ test ${ }^{\star} P<0.05,{ }^{* \star} P<0.01,{ }^{\star \star \star} P<0.001$ 
homologous recombination) or its downstream mediator MyD88. Conversely, adoptive transfer of TLR4-expressing DC loaded with dying tumor cells into TIr4 ${ }^{-/-}$mice restored the defective immune response, underscoring the crucial role of host antigen presenting cells harboring a functional TLR4/ MyD88 pathway for the recognition of ICD. The expression levels of TLR4 and MyD88 by the host immune system are essential for the control of established transplantable tumors including CT26 colorectal cancers, EG7 lymphomas, TS/A mammary carcinomas and GOS osteosarcomas by anthracyclines, oxaliplatin or radiotherapy. ${ }^{7,13}$

The clinical relevance of the TLR4 pathway for the success of anticancer therapies has been analyzed in several retrospective studies in early breast cancers (BCs), ${ }^{7}$ in metastatic colon cancers ${ }^{14}$ and in advanced non-small cell lung carcinoma. $^{15}$ A single-nucleotide polymorphism (SNP) rs4986790 affecting the TLR4 gene has been associated with decreased responses to the exogenous TLR4 ligand, bacterial lipopolysaccharide (LPS). ${ }^{16}$ This single-nucleotide substitution $(+896 \mathrm{~A} / \mathrm{G})$ in the TLR4 gene found in $12-15 \%$ of Caucasians leads to the replacement of an aspartic acid by a glycine residue (Asp299Gly) in the extracellular domain of TLR4. Coimmunoprecipitation experiments revealed that the variant form of TLR4 bound recombinant HMGB1 protein less efficiently than did unmutated TLR4. ${ }^{7}$ Moreover, although monocyte-derived DCs from individuals bearing the normal allele of TLR4 could cross-present antigens from dying melanoma cells to T cells in an HMGB1-dependent manner, DCs from individuals bearing the TLR4 Asp299Gly mutation failed to do so. ${ }^{7}$ Hence, the interactions between HMGB1 released by dying tumor cells and TLR4 present on DCs dictates the cross-presentation of tumor antigens to $\mathrm{T}$ cells and the priming of tumor-specific Tc1/Th1-cell responses mandatory for the success of anticancer therapies. ${ }^{7}$ Both in $\mathrm{BC}$ and colon cancer, individuals bearing one or two alleles of the rs4986790 SNP exhibited accelerated relapse after adjuvant chemotherapy with anthracyclines and oxaliplatin, respectively. ${ }^{7,14}$

HMGB1 has the role of an 'alarmin' or DAMP capable of recruiting and activating inflammatory phagocytes and eliciting adaptive immunity. ${ }^{2,17,18}$ Inside the cell, HMGB1 is ubiquitously present in the nucleus of most mammalian cells, in which it regulates gene transcription by promoting the access of transcriptional factors to the DNA. ${ }^{19}$ Although HMGB1 may stimulate tumor progression, metastasis and neoangiogenesis, ${ }^{20}$ HMGB1 expression was found downregulated in lung neoplasia ${ }^{21}$ and $\mathrm{BC}$ (our unpublished data). In such cases, chemotherapy-induced ICD could be severely compromised, pointing to the need of supplying artificial TLR4 ligands to restore chemosensitivity. Here, we addressed this issue showing that DEN, a chemically defined TLR4 agonist, markedly synergizes with anthracyclines or oxaliplatin and corrects the altered immunogenicity of HMGB1-deficient tumors. These findings open novel therapeutic avenues to improve the efficacy of cytotoxic compounds endowed with immunogenic potential and broaden the indications of TLR4 agonists in cancer.

\section{Results}

Deficiency in the nuclear expression of HMGB1 in two transplantable tumor models. HMGB1 expression was determined in paraffin-embedded CT26 colon carcinoma and MCA205 sarcoma tumors using immunhistochemical a
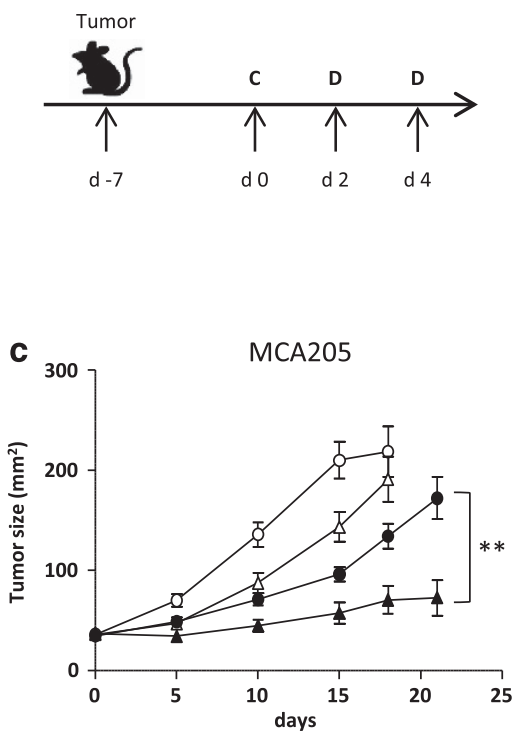
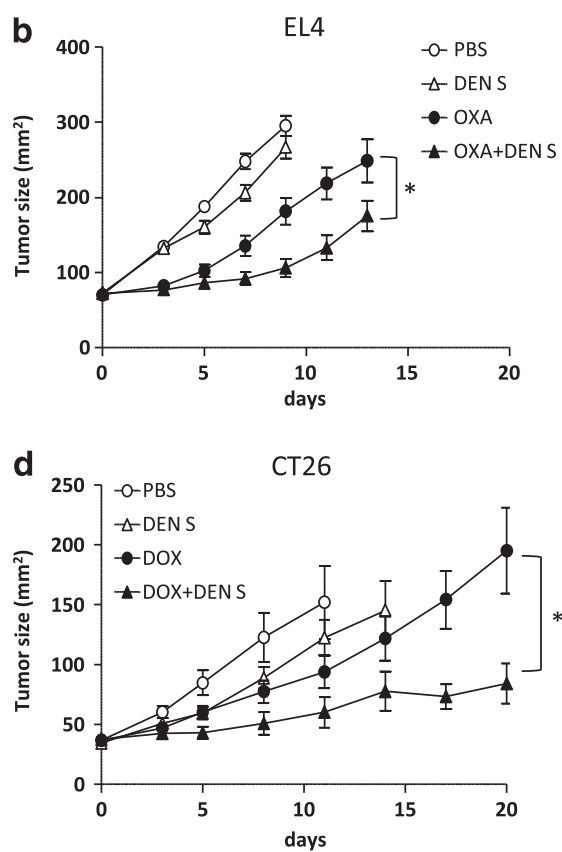

Figure 2 Synergistic effects between a TLR4/Myd88 agonist and immunogenic chemotherapeutic compounds. (a) Experimental setting. d: day, C: chemotherapy, D: DEN S. Day 7-established tumors (EL4 (b), MCA205 or CT26 (c) syngeneic of C57BL/6 (EL4, MCA205) or BALB/c mice (CT26) were treated with chemotherapy (intratumoral (c) or i.v. (b) injections of oxaliplatin (b) or anthracyclines (c)) followed by two i.v. administrations of DEN (days 2 and 4). Tumor growth was monitored and graphs represent mean tumor sizes \pm S.E.M. of 5-8 mice/group. ANOVA with the Newman-Keuls multiple comparison test: ${ }^{*} P<0.05,{ }^{* *} P<0.01$ 
analysis using a specific anti-HMGB1 antibody. ${ }^{22}$ This approach yielded a strong nuclear and cytoplasmic staining in cells that were cultured in vitro, pelleted and paraffin embedded (Figure 1a). Although all CT26 and MCA205 tumor cells stained positively after in vitro culture, a large fraction of them became negative after in vivo passage in immunocompetent BALB/C and C57BI6 mice, respectively (Figure 1a). Surrounding cells of the tumor stroma or lymph node exhibited a nuclear HMGB1 staining (Figure 1a, right panels) as an internal control, pointing to the differences between normal and cancer cells that arise in vivo. Of note, MCA205 fibrosarcomas almost completely lost nuclear HMGB1 expression (Figures 1a and b), whereas CT26 carcinomas conserved nuclear HMGB1 in $\sim 40 \%$ of malignant cells (Figures $1 a$ and $b$ ). This staining was strongly reduced upon transfection with an siRNA targeting HMGB1, confirming the specificity of the immunohistochemical method (Figures $1 \mathrm{c}$ and $\mathrm{d}$ ). We confirmed the relative and progressive loss of nuclear HMGB1 in human BCs by investigating the nuclear staining using the specific anti-HMGB1 Ab (Figure 1e). Out of 232 early BC treated by surgery, adjuvant anthracyclines and radiotherapy (+/-Tamoxifene in hormone receptor positive cancers), the loss of a nuclear staining was observed more frequently in large rather than small tumors (Figure $1 \mathrm{f} ;<60 \%$ for pT0, T1 versus $>70 \%$ for $>$ pT2, $P=0.042)$.

Hence, in both mouse sarcoma and colon carcinoma, as well as in human BC, a progressive loss of nuclear HMGB1 localization is gradually observed with tumor development.

Synergy between a TLR4 exclusive agonist and immunogenic cytotoxic agents. As HMGB1 is an endogenous TLR4 agonist, we investigated whether external supply of synthetic TLR4 agonists might be used as an adjunct therapy of tumor expressing low HMGB1 levels. As HMGB1 is normally released by dying cells at late time points (at least in vitro), we inoculated a TLR4-exclusive agonist called DEN (S301 or A201, DEN S or DEN A) intravenously shortly after the initiation of chemotherapy. DEN S and A (as described in the Materials and Methods ${ }^{23-27}$ ) are standardized, highly purified (>99.9\%) and physiochemically defined formulations of S- (wild-type, WT) and R-form LPS, respectively, ${ }^{28-30}$ devoid of proteins and other bacterial contaminants. ${ }^{31-38}$ DEN $S$ was inoculated 2 and 4 days post chemotherapy with oxaliplatin or doxorubicin (Figure 2a). This combined chemoimmunotherapeutic regimen yielded statistically significant synergistic effects against EL4 lymphomas (Figure 2b), MCA205 fibrosarcomas (Figure 2c, left panel) and a trend toward additive effects in CT26 carcinomas (Figure 2c, right panel). Thus, in EL4 and MCA205 tumors, chemotherapy with oxaliplatin and doxorubicin, respectively, had only mild effects that were exacerbated by co-treatment with DEN S, whereas DEN S on its own had no or little effects (Figures $2 b$ and c). Continuous chemo-immunotherapy of MCA205 fibrosarcomas with doxorubicin and DEN $S$ in four consecutive cycles every other 12 days (Figure 3a) achieved improved antitumor effects (Figure $3 \mathrm{~b}$ ) and conferred an increased long-term survival, eventually curing $20 \%$ animals (Figure 3c). Two routes of administration of DEN S, systemic intravenous injection versus local intratumoral inoculation, both performed at day 2 and 4 post chemotherapy, achieved similar antitumor effects (Supplementary Figure 1). A single inoculation of DEN $S$ at day 2 post-treatment with anthracyclines was sufficient for the chemo-immunotherapy regimen to exhibit significant synergy (Supplementary Figures $2 A-G$ ). The synergistic effect of Doxorubicin and DEN S was T-cell dependent as nu/nu mice were unable to control tumor growth (Supplementary Figures $2 \mathrm{H}$ and $\mathrm{I}$ )

Next, we evaluated the capacity of various TLR4 agonists to achieve a synergistic interaction with oxaliplatin (in EL4 thymoma, Figures $4 \mathrm{a}$ and c) or doxorubicin (in MCA205, Figures $4 \mathrm{~b}$ and $\mathrm{c}$ ). Escherichia coli-derived S-form LPS, which reportedly transduces a combined Myd88- and TIR-domaincontaining adapter-inducing interferon- $\beta$ (TRIF)-dependent signal, ${ }^{39,40}$ did not mediate significant effects in conjunction with chemotherapy (Figures $4 a$ and b). In contrast, both DEN $S$ and DEN A markedly synergized with either of the two cytotoxic agents (Figures $4 b$ and $c$ ). Both DEN S and DEN A weakly stimulated IL-6 release from murine cancer cell lines, yet failed to influence the growth of the cells in vitro.
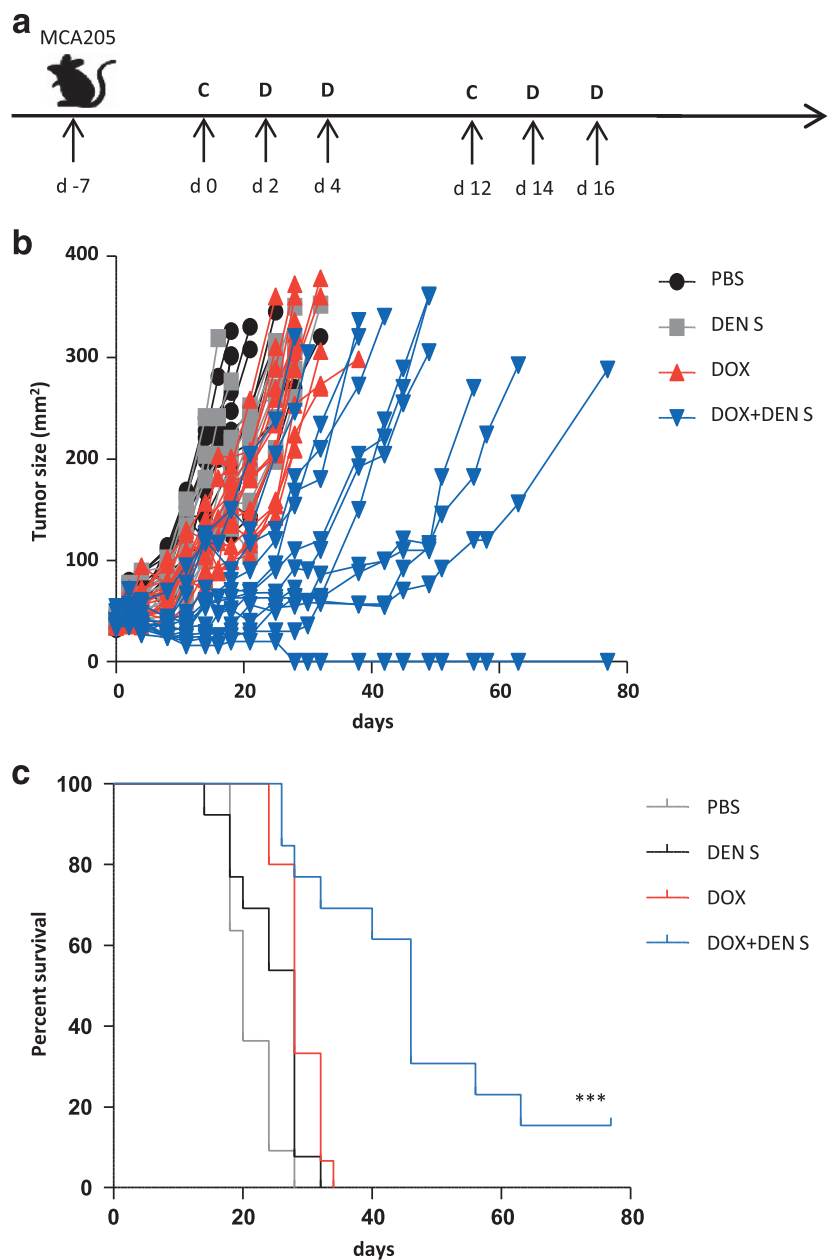

Figure 3 Long-term survival benefit using repeated cycles of concomitant chemoimmunotherapy. (a) Similar experimental setting as in Figure 1a, but each cycle is repeated every other 12 days. (b) Tumor growth curves for each mouse $(N=15 /$ group). (c) Kaplan-Meier survival curves for all 15 mice/group. Cox analyses ${ }^{* \star *} P<0.001$ 

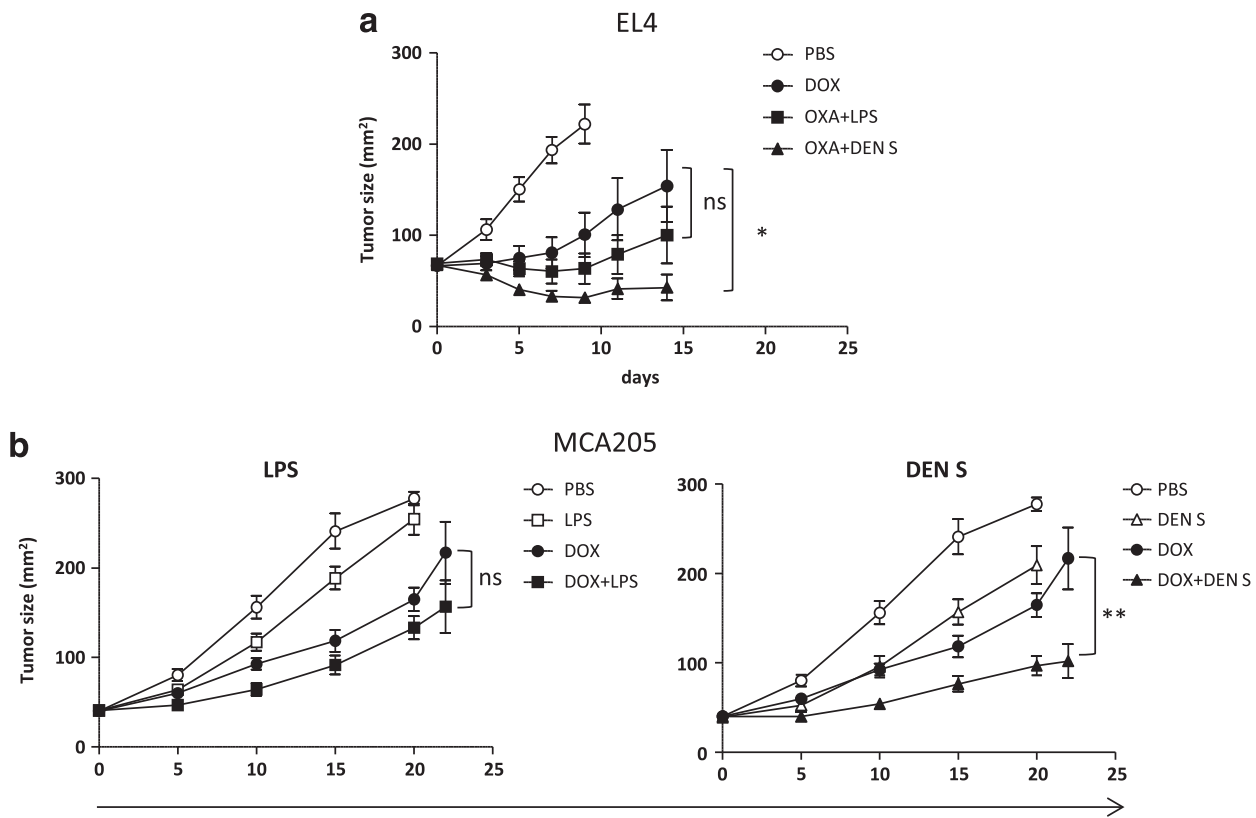

days
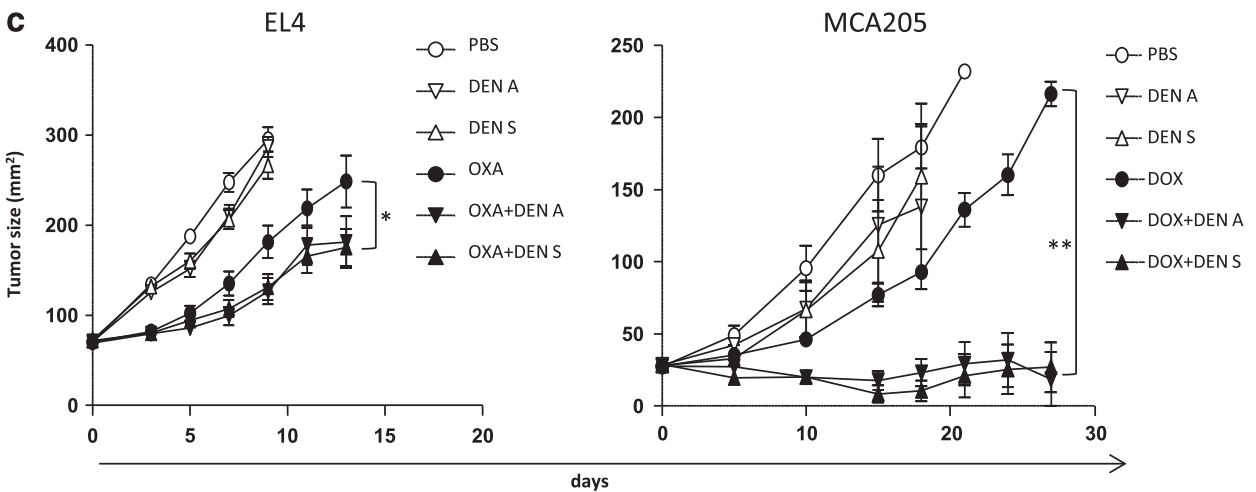

Figure 4 Effects of various TLR4 agonists on the efficacy of chemotherapy. Several TLR4 agonists (TRIF/Myd88-dependent agonists such as LPS (a and b), or Myd88dependent agonists ( $\mathbf{b}$ and $\mathbf{c}$ ) such as DEN S or DEN A) were coadministered with doxorubicin (a-c right panel) or oxaliplatin (c, left panel). Tumor (MCA205 or EL4) growth curves (Means \pm S.E.M.) are depicted. ANOVA with the Newman-Keuls multiple comparison test comparing all groups ${ }^{*} P<0.05,{ }^{\star *} P<0.01$

Altogether, these data suggest that the antitumor efficacy of chemotherapy can be greatly enhanced by chemically defined TLR4 agonists in various transplantable tumors expressing low levels of HMGB1.

Cellular and molecular mechanisms of the chemoimmunotherapy. The synergistic antitumor effects of DEN plus chemotherapy that we observed on tumors implanted in immunocompetent WT mice (Figures 2-4) were maintained in knockout mice lacking the TRIF (Figure 5a), indicating that TRIF was dispensable for signal transduction downstream of TLR4 in the host immune system. In sharp contrast, chemoimmunotherapy lost its efficacy on tumors implanted in mice lacking myeloid differentiation factor 88 (MyD88) (Figure 5b). Therefore, MyD88-dependent signaling appears to be required for the antitumor effects of DEN.

We next analyzed the phenotype of tumor-infiltrating leukocytes at days 7-10 post single or combination therapy. Chemo-immunotherapy markedly enhanced the intratumoral abundance of $\mathrm{CD} 45^{+}$leukocytes (Figure 6a). Myeloid cells
$\left(\mathrm{CD} 45^{+} \mathrm{CD}_{11 b^{+}}\right.$cells) (Figures $\left.\mathrm{b}-\mathrm{c}\right)$ decreased in number in favor of $\mathrm{CD}^{+}{ }^{+} \mathrm{T}$ lymphocytes (Figure $6 \mathrm{c}$ ), especially IFN $\gamma$ producing $\mathrm{CD}^{+}{ }^{+} \mathrm{Tc} 1$ cells and IFN $\gamma$-producing $\mathrm{CD}^{+}{ }^{+} \mathrm{Th} 1$ cells (Figure 6d). Interestingly, as recently reported, ${ }^{41}$ DEN S promoted the recruitment and/or the intratumoral differentiation of neutrophil granulocytes (Lin-CD11b ${ }^{+}$Ly6C $^{\text {low }}$, Ly6G $^{+}$ cells, Figure 6c). However, the antibody-mediated depletion of $\mathrm{Ly}_{6 \mathrm{G}}{ }^{+}$failed to abolish the efficacy of the chemoimmunotherapy, excluding the contribution of neutrophils to the anticancer effects of DEN (Supplementary Figure 3).

Altogether our data indicate that the synergistic antitumor effects achieved by the combination of DEN $A$ or $S$ plus chemotherapy with anthracyclines or oxaliplatin are mediated through the accumulation of intratumoral IFN $\gamma$-producing effector T lymphocytes.

Re-establishment of the immunogenicity of HMGB1deficient tumors by DEN. The standard assay for assessing the immunogenicity of cell death consists in exposing tumor cells in vitro to apoptosis inducers, followed by their 

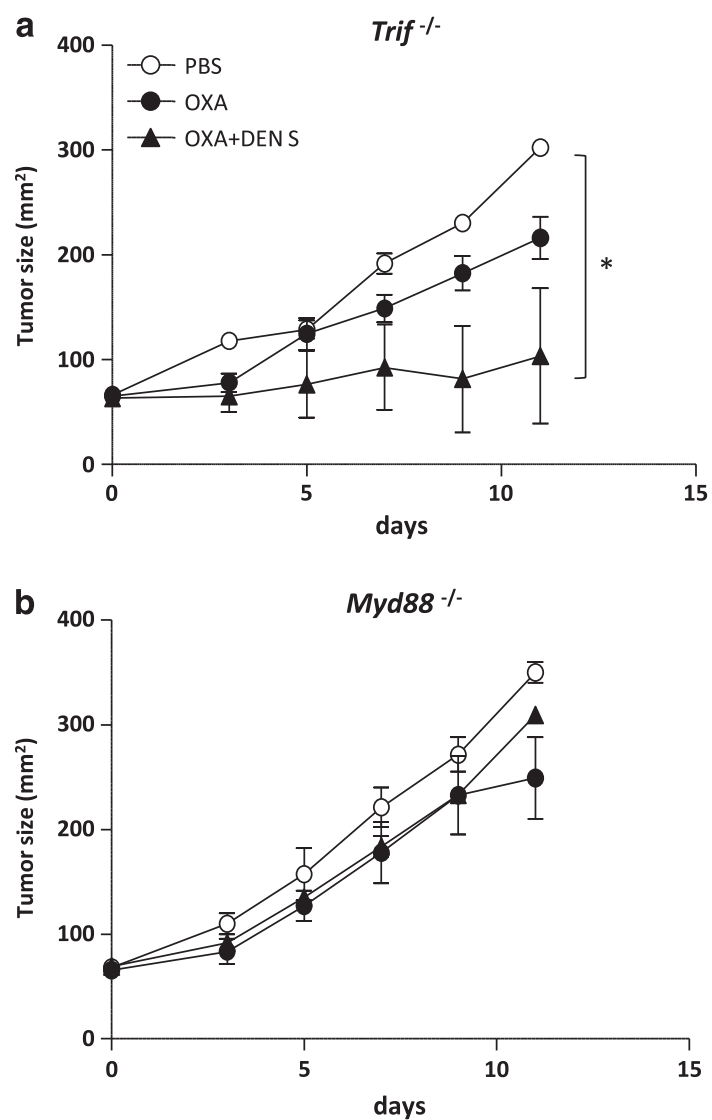

Figure 5 Myd88 but not TRIF is involved in the synergistic effects achieved with the chemoimmunotherapy. EL4 was established in two mouse species (TRIF (a) -or Myd88 (b)-deficient). Day 7-established tumors were treated according to the experimental setting described in Figure 1a. Tumor growth curves (Means \pm S.E.M.) are depicted. ANOVA with the Newman-Keuls multiple comparison test comparing all groups

subcutaneous injection into histocompatible immunocompetent mice, as $70 \pm 10 \%$ of the cells stain positively with annexin V-FITC and the vital dye propidium iodide. Eight to 10 days later, the mice are injected with live tumor cells into the opposite flank and tumor growth is monitored. The absence of tumor development then is interpreted as a sign of an anticancer immune response elicited by the vaccine. ${ }^{1,6}$ Depletion of HMGB1 from MCA205 cells with a specific siRNA validated by immunohistochemical (Figure 1c) or immunoblot analyses (Figure 1d) reduced their immunogenicity. This was observed in experiments in which MCA205 cells expressing or lacking HMGB1 were exposed to doxorubicin in vitro, washed, resuspended in PBS alone or PBS plus DEN $S$ and inoculated subcutaneously to immunize naive animals. Ten days later, all the mice were rechallenged with a lethal dose of non-transfected MCA205. Then, the tumor growth was monitored every 3 days (Figures $7 a$ and e), revealing that the vaccine consisting in doxorubicin-treated, HMGB1-expressing cells (that were either non-transfected of transfected with a scrambled control siRNA) was efficient in reducing tumor progression with or without the addition of exogenous DEN S (Figure 7e). In sharp contrast, immunization with doxorubin-treated MCA205 depleted from
HMGB1 failed to protect the mice against the rechallenge, except if the vaccine was combined with DEN S (Figure 7e). These results demonstrate that, in the context of deficient ICD, DEN $S$ can compensate for deficient HMGB1 expression.

\section{Discussion}

The foundations of cancer immunotherapy have been laid in the late 19th century when Coley observed that poorly defined bacterial extracts could induce the regression of bone sarcomas. Subsequent work demonstrated the capacity of bacterial compounds to elicit innate and cognate antitumor immune responses. ${ }^{42}$ Here, we show, in three distinct transplantable tumor models, that treatment with several conventional cytotoxic agents including doxorubicin and oxaliplatin, both of which induce ICD, markedly benefits from the adjunction of an exogenous TLR4 agonist, allowing to improve long-term survival in preclinical models (Figures 2-4). These synergistic antitumor effects led to the intratumoral accumulation of IFN $\gamma$ - producing $\mathrm{CD}^{+}{ }^{+}$and $\mathrm{CD}^{+}{ }^{+} \mathrm{T}$ cells (Figure 6), supporting the finding that they involve the same anticancer immune effectors as those that have been previously involved in the anticancer immune response elicited by doxorubicin and oxaliplatin alone..$^{4,5,7,8} \mathrm{We}$ also found that dying cancer cells lacking HMGB1 were unable to induce an anticancer immune response after chemotherapy unless they were combined with a chemically defined TLR4 agonist, DEN (Figure 7). Hence, three pieces of evidences now support the finding that the combination of anthracyclines and TLR4L is synergistic in a T-cell-dependent manner (augmentation of Th1/Tc1 TILs, no effect in nu/nu mice, induction of long-term immune memory responses).

In this work, we have administered various TLR4 agonists (such as E. coli S-form LPS and the DENs S and A) and found that only highly pure LPS preparations, enhanced the therapeutic efficacy of oxaliplatin or doxorubicin as illustrating by a stronger control of the tumor growth (Figure $4 a-b)$. Previously, we reported that host-derived TRIF is dispensable for the immune-dependent growth inhibition of transplantable tumors treated with anthracyclines or irradiation, whereas both TLR4 and MyD88 are absolutely required for the therapeutic effects of such anticancer agents. ${ }^{7}$ In fact, TLR9 ligands (CpG oligodeoxyribonucleotides), which are capable of inducing MyD88-dependent signals, could restore chemosensitivity in TLR4-deficient mice. ${ }^{13}$ The data indicate that DEN S and A are superior MyD88 activators than the standard LPS preparations available.

Both local and systemic administrations of TLR4/Myd88 agonist were equally efficient in synergizing with chemotherapy to reduce tumor growth (Supplementary Figure 1). We anticipate that the systemic application of TLR4 ligand may engage TLR4 on host antigen-presenting cells following the ATP- and purinergic receptor-dependent recruitment and differentiation of inflammatory monocytes Ly6C ${ }^{\text {high }}$ cells in close proximity with dying tumor cells. ${ }^{9}$ On its own, DEN S could significantly enhance the trafficking of leukocytes (more specifically CD $11 b^{+}$Ly $6 G^{+}$and Ly6C ${ }^{\text {high }}$ cells) into tumors, a phenomenon that might result from the mobilization of bone marrow precursors ${ }^{41}$ and/or spleen reservoirs. ${ }^{43}$ 

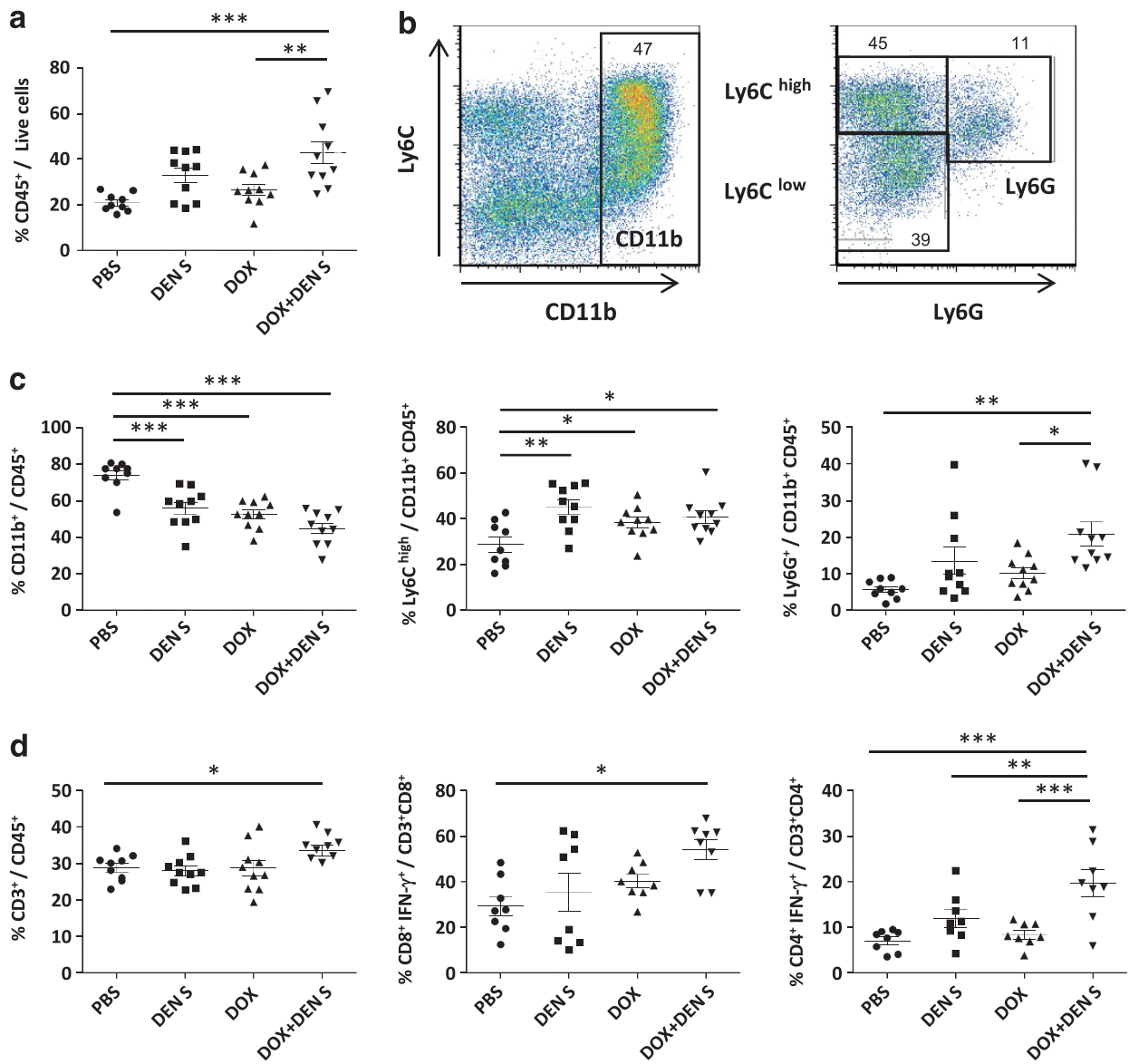

Figure 6 Chemoimmunotherapy promotes the accumulation of myelomonocytic and TH1/Tc1 infiltrates in tumor beds. (a-d) Flow cytometry analyses of several leukocytic subsets $\left(\mathrm{CD}_{4} 5^{+}(\mathbf{a}), \mathrm{CD}_{11 b^{+}}(\mathbf{b}\right.$ and $\mathbf{c}), \mathrm{CD}^{+}(\mathbf{d})$, gating on live cells after tumor harvesting at day 15 post-tumor inoculation. Intracellular staining of T lymphocytes investigating IFNg secretion after PMA/ionomycin $4 \mathrm{~h}$ restimulation (d). Subsets of myeloid cells analyzed on $\mathrm{CD} 11 \mathrm{~b}^{+} \mathrm{CD} 45^{+}$cells were analyzed using anti-Ly6G and Ly6C antibodies (b). Each dot represents one tumor. The data of three experiments are pooled for each group. ANOVA with the Newman-Keuls multiple comparison test comparing all groups ${ }^{*} P<0.05,{ }^{* *} P<0.01,{ }^{* * *} P<0.001$

Beyond its nuclear role, HMGB1 also functions as an extracellular cytokine-like molecule during various tumorrelevant pathological processes such as inflammation, cellular differentiation and migration. ${ }^{44-47}$ Indeed, HMGB1 can favor tumor progression through neoangiogenesis, presumably by attracting proangiogenic macrophages and endothelial cells in tumor beds, ${ }^{48}$ as well as by promoting sprouting of endothelial cells. ${ }^{20}$ Hence, HMGB1 is often considered as a protumorigenic factor associated with dismal prognosis. ${ }^{49,50}$ Accordingly, HMGB1-receptor for advanced glycation end products (RAGE) interactions have been described to stimulate invasion, migration and the growth of implanted gliomas. ${ }^{51}$ The replacement of HMGB1 by an exogenous compound capable of triggering TLR4 and the immunogenicity of cell death without favoring angiogenesis or invasion constitutes a challenge. Similar to most TLR agonists, TLR4 ligands may be considered as double-edged swords, as they not only bind to DC TLR4 to activate the immune system but also interact with TLR4 (or RAGE) on tumor cells to favor the manifestation of cell-intrinsic tumorigenic hallmarks and chemoresistance. ${ }^{52,53}$ In our model system, we ruled out the possibility that DEN would directly act on CT26, MCA205 or EL4 to enhance (or reduce) tumor cell proliferation (not shown). Moreover, a single injection at day 2 post chemotherapy was sufficient to amplify the immune effects of chemotherapy, bypassing the requirement for a prolonged exposure to TLR4 agonists (Supplementary Figure 2). Supplying tumor beds with a TLR4 agonist at the time of late apoptosis or necrosis could gear the phagocytosed antigenic cargo to the appropriate antigen-processing compartments, thus ensuring optimal processing and presentation of tumor antigens to $\mathrm{T}$ cells. ${ }^{7}$

Collectively, our data imply that combining anthracyclines or oxaliplatin with DEN may improve the $T$ cell-based immune responses accounting for prolonged anticancer effects. On theoretical grounds, this chemo-immunotherapy should be proposed to patients harboring HMGB1-deficient tumors but bearing a functional TLR (and hence lacking the lossof-function allele coding for TLR4 Asp299Gly). This strategy for the stratification of patients could add even more complexity to the current efforts of personalized therapy applied to breast tumors. ${ }^{54}$ Whether these approaches aimed at re-enforcing immunity will mainly benefit immune-prone neoplasia, ${ }^{54,55}$ or also improve the clinical management of immunosuppressed/ immunoedited cancers, needs to be determined in forthcoming clinical trials. 


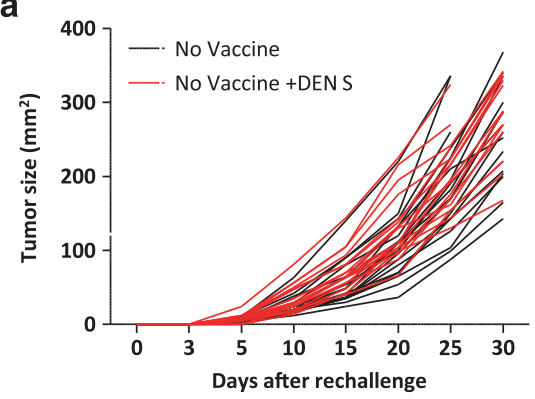

C

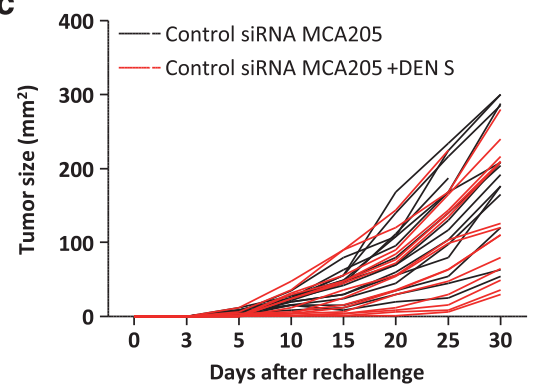

b

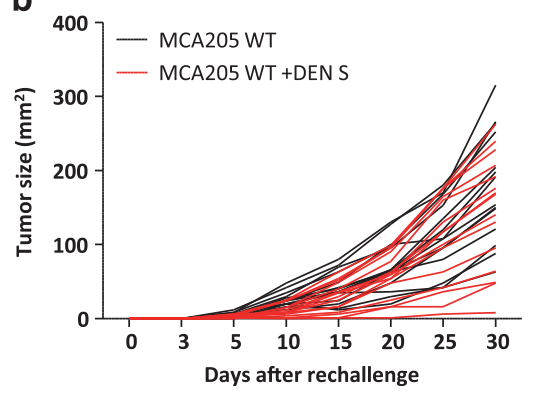

d

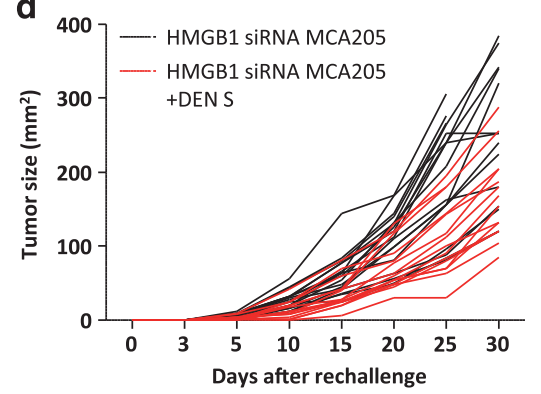

e ns

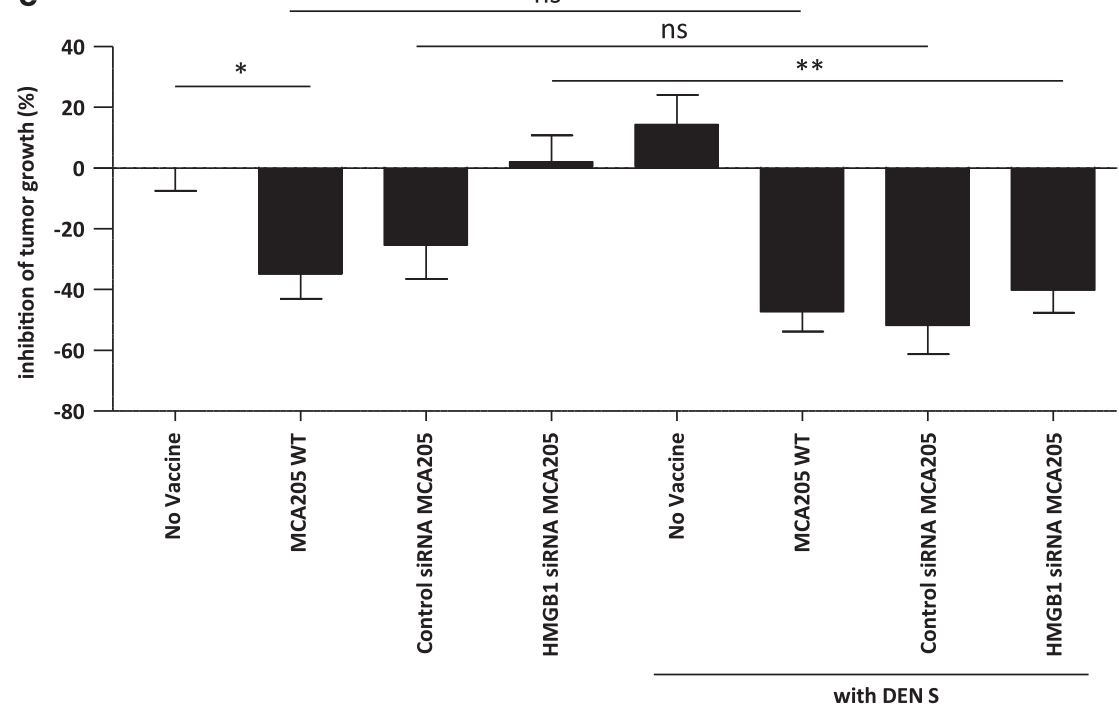

Figure 7 DEN compensates for the lack of immunogenicity of HMGB1-deficient tumors. (a-e) Knock down of HMGB1 in MCA205 tumors compromise the efficacy of the vaccine but can be compensated with a TLR4 agonist (DEN S). Graphs depict the growth curves of the rechallenge after immunization of naive mice with dying tumor cells + I - DEN. $N=15$ mice/groups (gathering two independent experiments). (e) The percentages of growth inhibition comparing each group of mice with unvaccinated animals are shown. ANOVA with the Newman-Keuls multiple comparison test comparing all groups ${ }^{\star} P<0.05,{ }^{* *} P<0.01,{ }^{* \star *} P<0.001$

\section{Materials and Methods}

Mouse strains. All animals were bred and maintained according to both the FELASA and the Animal Experimental Ethics Committee Guidelines (Val de Marne, France). WT SPF C57BL/6J and BALB/c mice were obtained from Harlan or Janvier, and Myd88 ${ }^{-1-}$ and Trif $^{-1-}$ C57BL/6J mice were provided by B.Ryffel (CNRS, France) and were maintained in controlled, pathogen-free conditions at the Institut Gustave Roussy (IGR, Villejuif, France) and used at between 7 and 18 weeks of age. Nu/nu mice were breed and maintained in IGR animal facility and used between 7 and 18 weeks of age.

Reagents and materials. Cell death was induced either with Doxorubicin (Sigma Aldrich, St Louis, MO, USA) or Oxaliplatin (Sanofi-Aventis, Paris, France). LPS from E. coli serotype 055:B5 was obtained from Sigma-Aldrich. Anti-mouse antibodies for $\mathrm{CD} 3 \varepsilon$ (145-2C11), CD4 (GK1.5), CD8 $\alpha$ (53-6.7), CD11b (M1/70),
CD16/32 (2.4G2), CD45.2 (104), Ly6c (AL-21), Ly6g (RG6-8C5), IFN- $\gamma$ (XMG1.2) and IL-17 (eBio17B7) were obtained from BD Bioscience (San Jose, CA, USA), BioLegend (San Diego, CA, USA) and eBioscience (San Diego, CA, USA). LIVE/ $D E A D$ fixable yellow stain fluorescence for viability staining was purchased from Invitrogen (Carlsbad, CA, USA). Cell acquisition and analysis have been performed on a Cyan (Beckman Colter) flow cytometer with FlowJo software 7.6.3 (Tree Star, Ashland, OR, USA).

TLR4 exclusive agonists. DEN S301 and A201 (DEN S and DEN A) (provided by Innaxon, Tewkesbury, UK) have been isolated according to an optimized and standardized proprietary protocol, based upon the methods described by Galanos, Westphal and Lüderitz, ${ }^{23-27}$ which involves optimized fermentation conditions and multistep purification steps and subsequent electrodialysis in order to separate cations and basic amines, which impact on 
the physiochemical properties and corresponding biological properties, such as complement activation, binding to serum proteins, in vivo distribution, toxicity and antitumor activity. A broad level of analytical methods assured the complete removal of macromolecular contaminants (undetectable levels corresponding to $<0.01 \%$ ), such as proteins, nucleic acids and sugar polymers, ${ }^{56-60}$ with exclusive binding to TLR4 confirmed in primary TLR4 WT and deficient mouse macrophage cell lines. DEN $S$ is a standardized formulation of (S-form) LPS, whereas DEN A represents an R-form LPS, both in a highly water soluble preparation as a uniform salt with a constant sediment coefficient. Any trace lipoproteins bound to the LPS molecule have been removed. In contrast, certain chemical modifications of the core and Lipid A moiety only found in natural LPS, selected for maximal potency to elicit an antitumor immunity in rodent models and in humans have been preserved. ${ }^{31-38}$

Transplantable tumor cell lines. CT26 colon cancer cells (syngenic from BALB/c mice), EL4 thymoma cells (syngenic from C57BL/6 mice) and MCA205 fibrosarcoma cells (syngenic from C57BL/6 mice) were cultured at $37^{\circ} \mathrm{C}$ under $5 \%$ $\mathrm{CO}_{2}$ in RPMI 1640 containing $10 \% \mathrm{FCS}, 2 \mathrm{~mm}$ L-glutamine, $100 \mathrm{IU} / \mathrm{ml}$ penicillin/ streptomycin, $1 \mathrm{mM}$ sodium pyruvate and MEM nonessential amino acids (Invitrogen)

Chemotherapy and DEN treatment of established tumors in mice. WT or loss-of-function mice were injected in the right flank with $1 \times 10^{6}$ of EL4 or CT26 or MCA205 cells. The mice were then randomly assigned into treatment groups comprising 4-6 mice each. When tumor size reached $35-50 \mathrm{~mm}^{2}$, the mice were treated with oxaliplatin ( $5 \mathrm{mg}$ per $\mathrm{kg}$ body weight i.p for EL4), doxorubicin $(2 \mu \mathrm{M}$ injected intratumorally in $100 \mu \mathrm{l}$ of PBS, for CT26 and MCA205). Two and/or four days after chemotherapy, the mice were treated with DEN or $E$. coli S-form LPS 055:B5 (2 $\mu \mathrm{g}$ in $100 \mu \mathrm{l} 0.9 \% \mathrm{NaCl}$ per mouse i.v or i.t). In some experiments, MCA205 tumor-bearing mice received doxorubicin and DEN every 12 days after first treatment. Tumor growths were monitored every 3-4 days using a caliper.

Immunoblot analysis. For immunoblot analysis, cells were washed in cold PBS and lysed in a sample buffer containing $1 \%$ vol/vol NP40, $20 \mathrm{mM}$ HEPES (pH 7.9), $10 \mathrm{mM} \mathrm{KCl}, 1 \mathrm{mM}$ EDTA, $1 \mathrm{mM}$ PMSF, $1 \%$ vol/vol glycerol and protease and phosphatase inhibitors. We separated $15 \mathrm{mg}$ proteins on $10 \%$ SDS-PAGE gels and electrotransferred them to nitrocellulose membranes (iBlot Western Detection Kit, Invitrogen). After blocking with $3 \% \mathrm{wt} / \mathrm{vol} \mathrm{BSA}$ and $0.1 \% \mathrm{vol} / \mathrm{vol}$ Tween-20, we used primary antibodies for HMGB1 and GAPDH. Finally, bound antibodies were detected with the appropriate horseradish peroxidase-labeled secondary antibodies and ECL Plus detection system.

RNA interference knockdown of HMGB1. We transfected MCA205 cells using Lipofectamine RNAiMAX (Invitrogen) with either PBS, irrelevant siRNA (5'-CUUACGCUGAGUACUUCGATT-3'), HMGB1 SIRNA 1 (5'-GCAGCCCUAU GAGAAGAAATT-3') or HMGB1 siRNA 2 (5'-GCUGAAAAGAGCAAGAAAATT-3'). The depletion of HMGB1 was assessed $48 \mathrm{~h}$ after each transfection by immunoblot analysis as described above.

Anticancer vaccination. MCA205 cells or transfected with HMGB1 siRNA or irrelevant siRNA cells were cultured in vitro in the presence of doxorubicin $(1 \mu \mathrm{M})$ for $24 \mathrm{~h}$. siRNA transfected cells were treated with doxorubicin post $48 \mathrm{~h}$ transfection. Dying cells $\left(1 \times 10^{6}\right)$ were injected subcutaneously into the right footpad of mice. Ten days later, the mice were rechallenged in the right flank with $5 \times 10^{5}$ live MCA205 cells. Tumor growth was monitored every $2-5$ days using a caliper.

Tumor infiltrating lymphocytes analysis. At indicated time points, tumors were harvested, cut into small pieces and digested in Liberase TM (Roche, Penzberg, Germany) and DNase I (Calbiochem, San Diego, CA, USA) for 30 min at $37^{\circ} \mathrm{C}$. Single-cell suspension was obtained by crushing the digested tissue with a syringe plunger and filtering through a $100-\mu \mathrm{m}$ cell strainer. For intracellular staining of cells, cells were incubated for $4 \mathrm{~h}$ at $37^{\circ} \mathrm{C}$ with $50 \mathrm{ng} / \mathrm{ml}$ of PMA, $1 \mu \mathrm{g} /$ $\mathrm{ml}$ of ionomycin and BD Golgi STO. After membrane staining, cells were stained with anti-IL-17, IFN $\gamma$ using BD Cytofix/Cytoperm Kit, according to the manufacturer's instructions.

HMGB1 immunostaining. MCA205 and siRNA transfected cells were fixed with formol/eosine and embedded in paraffin. Five- $\mu$ m-thick tissue sections were obtained with a microtome (MEDITE, Winter Garden, FL, USA) and adhered to poly-L-lysine-coated slides, deparaffinized and hydrated through graded alcohols to water. Sections were pretreated with citrate buffer (DiaPath, Bergamo, Italy), $\mathrm{pH}$ 6 , for $20 \mathrm{~min}$ in a $98^{\circ} \mathrm{C}$ water bath. Endogenous peroxidase activity was inhibited with 3\% hydrogen peroxidase (Dako, Glostrup, Denmark) for $10 \mathrm{~min}$. Sections were then saturated $20 \mathrm{~min}$ with Protein Block Serum-Free (Dako). Without washing, the primary antibody, a polyclonal rabbit anti HMGB1 antibody (ThermoScientist Pierce), was incubated overnight, followed by the secondary Ab, (En vision-Rabbit, Dako) for $30 \mathrm{~min}$, and the streptavidin-HRP was incubated for an additional $30 \mathrm{~min}$. Peroxidases were detected with Diaminobenzidine substrate (DAB, Dako), and the sections were counterstained with Mayer's hematoxylin.

Statistical analyses. Unless otherwise indicated, results are expressed as mean \pm S.E.M. All experiments were repeated at least twice, yielding similar results. Normal distributions were compared using unpaired, two-tailed Student's t-tests or ANOVA with the Newman-Keuls multiple comparison test. Statistical analyses were performed by means of the software Prism 5 (GraphPad, San Diego, CA, USA) or Excel 2010 (Microsoft, Rockville, MD, USA). P-values $<0.05$ were considered as statistically significant.

\section{Conflict of Interest}

The authors declare no conflict of interest.

Acknowledgements. We thank Innaxon, UK for the support of this study through the generous provision of DENand Dr. Frank Neumann (Innaxon) for useful discussions and comments on the selection and application of DEN preparations. This work was supported by Institut National du Cancer (INCa), la Ligue contre le cancer (LIGUE labellisée, Zitvogel L, LIGUE (NP, AS)), l'Association pour la Recherche sur le Cancer (ARC); Fondation pour la Recherche Médicale and Fondation de France, SIRIC, PACRI, LABEX ImmunoONcology. GK is supported by the European Research Council (ERC); European Commission (ArtForce); Agence National de la Recherche (ANR); Ligue contre le Cancer (Equipe labellisée); Fondation pour la Recherche Médicale (FRM); Institut National du Cancer (INCa); LabEx Immuno-Oncologie; Fondation de France; Fondation Bettencourt-Schueller; AXA Chair for Longevity Research; Cancéropôle lle-deFrance and Paris Alliance of Cancer Research Institutes (PACRI).

1. Kroemer G, Galluzzi L, Kepp O, Zitvogel L. Immunogenic cell death in cancer therapy. Annu Rev Immunol 2013; 31: 51-72.

2. Krysko DV, Garg AD, Kaczmarek A, Krysko $O$, Agostinis $P$, Vandenabeele $P$. Immunogenic cell death and DAMPs in cancer therapy. Nat Rev Cancer 2012; 12: 860-875.

3. Zitvogel L, Kepp O, Kroemer G. Decoding cell death signals in inflammation and immunity. Cell 2010; 140: 798-804.

4. Ghiringhelli F, Apetoh L, Tesniere A, Aymeric L, Ma Y, Ortiz C et al. Activation of the NLRP3 inflammasome in dendritic cells induces IL-1beta-dependent adaptive immunity against tumors. Nat Med 2009; 15: 1170-1178.

5. Michaud M, Martins I, Sukkurwala AQ, Adjemian S, Ma Y, Pellegatti P et al. Autophagydependent anticancer immune responses induced by chemotherapeutic agents in mice. Science 2011; 334: 1573-1577.

6. Obeid M, Tesniere A, Ghiringhelli F, Fimia GM, Apetoh L, Perfettini JL et al. Calreticulin exposure dictates the immunogenicity of cancer cell death. Nat Med 2007; 13: 54-61.

7. Apetoh L, Ghiringhelli F, Tesniere A, Obeid M, Ortiz C, Criollo A et al. Toll-like receptor 4-dependent contribution of the immune system to anticancer chemotherapy and radiotherapy. Nat Med 2007; 13: 1050-1059.

8. Ma Y, Aymeric L, Locher C, Mattarollo SR, Delahaye NF, Pereira P et al. Contribution of IL-17-producing gamma delta $T$ cells to the efficacy of anticancer chemotherapy. J Exp Med 2011; 208: 491-503.

9. Ma Y, Adjemian S, Mattarollo SR, Yamazaki T, Aymeric L, Yang $\mathrm{H}$ et al. Anticancer chemotherapy-induced intratumoral recruitment and differentiation of antigen-presenting cells. Immunity 2013; 38: 729-741.

10. Takeda K, Kaisho T, Akira S. Toll-like receptors. Annu Rev Immunol 2003; 21: 335-376.

11. Marshak-Rothstein A. Toll-like receptors in systemic autoimmune disease. Nat Rev Immunol 2006; 6: 823-835.

12. Shiratsuchi A, Watanabe I, Takeuchi O, Akira S, Nakanishi Y. Inhibitory effect of Toll-like receptor 4 on fusion between phagosomes and endosomes/lysosomes in macrophages. J Immunol 2004; 172: 2039-2047.

13. Apetoh L, Ghiringhelli F, Tesniere A, Criollo A, Ortiz C, Lidereau R et al. The interaction between HMGB1 and TLR4 dictates the outcome of anticancer chemotherapy and radiotherapy. Immunol Rev 2007; 220: 47-59. 
14. Tesniere A, Schlemmer F, Boige V, Kepp O, Martins I, Ghiringhelli F et al. Immunogenic death of colon cancer cells treated with oxaliplatin. Oncogene 2010; 29: 482-491.

15. Vacchelli E, Galluzzi L, Rousseau V, Rigoni A, Tesniere A, Delahaye N et al. Loss-of-function alleles of P2RX7 and TLR4 fail to affect the response to chemotherapy in non-small cell lung cancer. Oncoimmunology 2012; 1: 271-278.

16. Arbour NC, Lorenz E, Schutte BC, Zabner J, Kline JN, Jones M et al. TLR4 mutations are associated with endotoxin hyporesponsiveness in humans. Nat Genet 2000; 25: 187-191.

17. Oppenheim JJ, Yang D. Alarmins: chemotactic activators of immune responses. Curr Opin Immunol 2005; 17: 359-365.

18. Rovere-Querini P, Capobianco A, Scaffidi P, Valentinis B, Catalanotti F, Giazzon M et al. HMGB1 is an endogenous immune adjuvant released by necrotic cells. EMBO Rep 2004 5: 825-830.

19. Joshi SR, Sarpong YC, Peterson RC, Scovell WM. Nucleosome dynamics: HMGB1 relaxes canonical nucleosome structure to facilitate estrogen receptor binding. Nucleic Acids Res 2012; 40: 10161-10171.

20. Jube S, Rivera ZS, Bianchi ME, Powers A, Wang E, Pagano I et al. Cancer cell secretion of the DAMP protein HMGB1 supports progression in malignant mesothelioma. Cancer Res 2012; 72: 3290-3301.

21. Shen $X$, Hong $L$, Sun $H$, Shi M, Song $Y$. The expression of high-mobility group protein box 1 correlates with the progression of non-small cell lung cancer. Oncol Rep 2009; 22: 535-539.

22. Ladoire S, Hannani D, Vetizou M, Locher C, Aymeric L, Apetoh L et al. Cell-deathassociated molecular patterns as determinants of cancer immunogenicity. Antioxid Redox Signal (e-pub ahead of print 20 March 2013).

23. Galanos C, Jiao BH, Komuro T, Freudenberg MA, Luderitz O. Large-scale fractionation of S-form lipopolysaccharide from Salmonella abortus equi. Chemical and serological characterization of the fractions. J Chromatogr 1988; 440: 397-404.

24. Galanos C, Luderitz O. Electrodialysis of lipopolysaccharides and their conversion to uniform salt forms. Eur J Biochem 1975; 54: 603-610.

25. Galanos C, Luderitz O, Himmelspach K. The partial acid hydrolysis of polysaccharides: a new method for obtaining oligosaccharides in high yield. Eur J Biochem 1969; 8: 332-336.

26. Galanos C, Luderitz O, Westphal O. A new method for the extraction of R lipopolysaccharides. Eur J Biochem 1969; 9: 245-249.

27. Galanos C, Luderitz O, Westphal O. Preparation and properties of a standardized lipopolysaccharide from Salmonella abortus equi (Novo-Pyrexal). Zentralbl Bakteriol Orig A 1979; 243: 226-244.

28. Huber M, Kalis C, Keck S, Jiang Z, Georgel P, Du X et al. R-form LPS, the master key to the activation ofTLR4/MD-2-positive cells. Eur J Immunol 2006; 36: 701-711.

29. Jiang Z, Georgel P, Du X, Shamel L, Sovath S, Mudd S et al. CD14 is required for MyD88-independent LPS signaling. Nat Immunol 2005; 6: 565-570.

30. Poltorak A, He X, Smirnova I, Liu MY, Van Huffel C, Du X et al. Defective LPS signaling in $\mathrm{C} 3 \mathrm{H} / \mathrm{HeJ}$ and $\mathrm{C} 57 \mathrm{BL} / 10 \mathrm{ScCr}$ mice: mutations in Tlr4 gene. Science 1998; 282 : 2085-2088.

31. Bartholeyns J, Freudenberg M, Galanos C. Growing tumors induce hypersensitivity to endotoxin and tumor necrosis factor. Infect Immun 1987; 55: 2230-2233.

32. Chokri M, Freudenberg M, Galanos C, Poindron P, Bartholeyns J. Antitumoral effects of lipopolysaccharides, tumor necrosis factor, interferon and activated macrophages: synergism and tissue distribution. Anticancer Res 1989; 9: 1185-1190.

33. Engelhardt R, Mackensen A, Galanos C. Phase I trial of intravenously administered endotoxin (Salmonella abortus equi) in cancer patients. Cancer Res 1991; 51: 2524-2530.

34. Engelhardt R, Otto F, Mackensen A, Mertelsmann R, Galanos C. Endotoxin (Salmonella abortus equi) in cancer patients. Clinical and immunological findings. Prog Clin Biol Res 1995; 392: 253-261.

35. Freudenberg N, Joh K, Westphal O, Mittermayer C, Freudenberg MA, Galanos C. Haemorrhagic tumour necrosis following endotoxin administration. I. Communication: morphological investigation on endotoxin-induced necrosis of the methylcholanthrene (Meth A) tumour in the mouse. Virchows Arch A Pathol Anat Histopathol 1984; 403: 377-389.

36. Rietschel ET, Galanos C, Tanaka A, Ruschmann E, Luderitz O, Westphal O. Biological activities of chemically modified endotoxins. Eur J Biochem 1971; 22: 218-224.

37. Strittmatter W, Galanos C. Characterisation of protein co-extracted together with LPS in Escherichia coli, Salmonella minnesota and Yersinia enterocolitica. Microb Pathog 1987; 2 29-36.
38. Vedder H, Schreiber W, Yassouridis A, Gudewill S, Galanos C, Pollmacher T. Dose-dependence of bacterial lipopolysaccharide (LPS) effects on peak response and time course of the immune-endocrine host response in humans. Inflamm Res 1999; 48: 67-74.

39. Fitzgerald KA, Rowe DC, Barnes BJ, Caffrey DR, Visintin A, Latz E et al. LPS-TLR4 signaling to IRF-3/7 and NF-kappaB involves the toll adapters TRAM and TRIF. J Exp Med 2003; 198: 1043-1055.

40. Kawai T, Adachi O, Ogawa T, Takeda K, Akira S. Unresponsiveness of MyD88-deficient mice to endotoxin. Immunity 1999; 11: 115-122.

41. Bugl S, Wirths S, Radsak MP, Schild H, Stein P, Andre MC et al. Steady-state neutrophil homeostasis is dependent on TLR4/TRIF signaling. Blood 2012; 121: 723-733.

42. Galluzzi L, Vacchelli E, Eggermont A, Fridman WH, Galon J, Sautes-Fridman C et al. Trial watch: experimental Toll-like receptor agonists for cancer therapy. Oncoimmunology 2012; 1: 699-716.

43. Cortez-Retamozo V, Etzrodt M, Newton A, Rauch PJ, Chudnovskiy A, Berger C et al Origins of tumor-associated macrophages and neutrophils. Proc Natl Acad Sci USA 2012; 109: 2491-2496.

44. Muller S, Scaffidi P, Degryse B, Bonaldi T, Ronfani L, Agresti A et al. New EMBO members' review: the double life of HMGB1 chromatin protein: architectural factor and extracellula signal. EMBO J 2001; 20: 4337-4340.

45. Lotze MT, Tracey KJ. High-mobility group box 1 protein (HMGB1): nuclear weapon in the immune arsenal. Nat Rev Immunol 2005; 5: 331-342.

46. Ellerman JE, Brown CK, de Vera M, Zeh HJ, Billiar T, Rubartelli A et al. Masquerader: high mobility group box-1 and cancer. Clin Cancer Res 2007; 13: 2836-2848.

47. Dong Xda E, Ito N, Lotze MT, Demarco RA, Popovic P, Shand SH et al. High mobility group box I (HMGB1) release from tumor cells after treatment: implications for development of targeted chemoimmunotherapy. J Immunother 2007; 30: 596-606.

48. Venneri MA, De Palma M, Ponzoni M, Pucci F, Scielzo C, Zonari E et al. Identification of proangiogenic TIE2-expressing monocytes (TEMs) in human peripheral blood and cancer. Blood 2007; 109: 5276-5285.

49. Nestl A, Von Stein OD, Zatloukal K, Thies WG, Herrlich P, Hofmann M et al. Gene expression patterns associated with the metastatic phenotype in rodent and human tumors. Cancer Res 2001; 61: 1569-1577.

50. Poser I, Golob M, Buettner R, Bosserhoff AK. Upregulation of HMG1 leads to melanoma inhibitory activity expression in malignant melanoma cells and contributes to their malignancy phenotype. Mol Cell Biol 2003; 23: 2991-2998.

51. Yu W, Kim J, Ossowski L. Reduction in surface urokinase receptor forces malignant cells into a protracted state of dormancy. J Cell Biol 1997; 137: 767-777.

52. Conforti R, Ma Y, Morel Y, Paturel C, Terme M, Viaud S et al. Opposing effects of toll-like receptor (TLR3) signaling in tumors can be therapeutically uncoupled to optimize the anticancer efficacy of TLR3 ligands. Cancer Res 2010; 70: 490-500.

53. Oblak A, Jerala R. Toll-like receptor 4 activation in cancer progression and therapy. Clin Dev Immunol 2011; 2011: 609579.

54. Andre F, Nowak F, Arnedos M, Lacroix L, Viens P, Calvo F. Biomarker discovery, development, and implementation in France: a report from the French National Cancer Institute and cooperative groups. Clin Cancer Res 2012; 18: 1555-1560.

55. Messina JL, Fenstermacher DA, Eschrich S, Qu X, Berglund AE, Lloyd MC et al. 12-Chemokine gene signature identifies lymph node-like structures in melanoma: potential for patient selection for immunotherapy? Sci Rep 2012; 2: 765.

56. Freudenberg MA, Fomsgaard A, Mitov I, Galanos C. ELISA for antibodies to lipid A, lipopolysaccharides and other hydrophobic antigens. Infection 1989; 17: 322-328.

57. Galanos $C$, Luderitz $O$, Westphal $O$. Preparation and properties of antisera against the lipid-A component of bacterial lipopolysaccharides. Eur J Biochem 1971; 24: 116-122.

58. Komuro T, Yomota C, Kimura T, Galanos C. Comparison of R- and S-form lipopolysaccharides fractionated from Escherichia coli UKT-B lipopolysaccharide in pyrogen and Limulus tests. FEMS Microbiol Lett 1989; 51: 79-83.

59. Schlecht S, Freudenberg MA, Galanos C. Immunoblot analysis of the R-form lipopolysaccharide from Salmonella S forms. Zentralbl Bakteriol 1992; 277: 288-295.

60. Yin ET, Galanos C, Kinsky S, Bradshaw RA, Wessler S, Luderitz $O$ et al. Picogramsensitive assay for endotoxin: gelation of Limulus polyphemus blood cell lysate induced by purified lipopolysaccharides and lipid A from Gram-negative bacteria. Biochim Biophys Acta 1972; 261: 284-289. 